\title{
Hypoglycaemia following upper gastrointestinal surgery: case report and review of the literature
}

Brandon Bernard', Gregory A Kline ${ }^{1 *}$, F John Service ${ }^{2}$

\begin{abstract}
Background: Hyperinsulinemic hypoglycemia is relatively recently recognized in persons undergoing bariatric surgery although knowledge and experience with this condition may not be commensurate with the number of such procedures being performed globally. This paper presents a novel case as an example of how such patients may present and how they may be investigated.

Case Presentation: A 69-year-old man was assessed 3 months post-fundoplication surgery for postprandial hypoglycaemia with neuroglycopenia that became progressively severe. A 72-h fast failed to show hypoglycaemia. During a clinic visit, the patient became confused and had a low plasma glucose, high plasma insulin, and high plasma C-peptide; symptoms were relieved with glucose. No tumours were visualized on CT, MRI, or endoscopic ultrasound. A total body Indium111-octreotide scan was negative. Selective arterial calcium stimulation showed a high insulin gradient in the splenic and superior mesenteric arteries, suggesting diffuse pancreatic beta cell hyperplasia. The patient declined pancreatic resection and recurrent symptomatic hypoglycaemia was successfully prevented with low dose octreotide.

Conclusions: Although increasingly recognized following bariatric surgery, this is the first reported development of NIPHS (non-insulinoma pancreatogenous hypoglycemia syndrome) following fundoplication surgery, as well as the first documented use of octreotide in post-operative NIPHS. Medical management may be an alternative to surgery for patients with this rare condition.
\end{abstract}

\section{Background}

It is common to see patients presenting with symptoms attributed to "hypoglycaemia" in endocrinology and general medicine clinics. The first step in evaluation requires documentation that hypoglycaemia is in fact present and the cause of the symptoms. Once hypoglycaemia is proven, the next step is to determine whether it is mediated by insulin or by an alternate disease process. Most insulinmediated hypoglycaemia is due to either exogenous insulin use or the presence of an insulinoma but in recent years, the differential diagnosis has expanded to include other forms of beta cell dysfunction, some of which may simulate insulinoma, as illustrated in the following case.

\section{Case presentation}

A 69-year-old non-obese man (BMI $25.2 \mathrm{~kg} / \mathrm{m}^{2}$ ) presented with a 3 month history of progressive symptoms

\footnotetext{
* Correspondence: gakline@ucalgary.ca

'Division of Endocrinology, Faculty of Medicine, University of Calgary, Calgary, Alberta Canada
}

of hypoglycaemia following meals. He noted that symptoms first appeared 14 years ago at which time a formal 72 hour fast failed to show any hypoglycaemia. However, his symptoms had become dramatically worse 2 months after undergoing a recent Nissan fundoplication surgery to repair a paraesophageal hiatus hernia. The episodes were characterized by agitation, sweatiness, rapid heart rate, tremor, light headedness, confusion and cognitive changes likened to alcohol intoxication that occurred an hour or two after meals. One such episode had resulted in loss of consciousness and subsequent involvement in a motor vehicle crash. There were no nocturnal symptoms and no history of weight loss, abdominal pain or diarrhoea. He denied the use of oral hypoglycaemic agents or insulin.

Initial investigations were performed during his first clinical visit when the patient was noticed to become diaphoretic and confused during the history and physical examination. The onset of these symptoms occurred at approximately 1.5 hours after breakfast. Plasma 


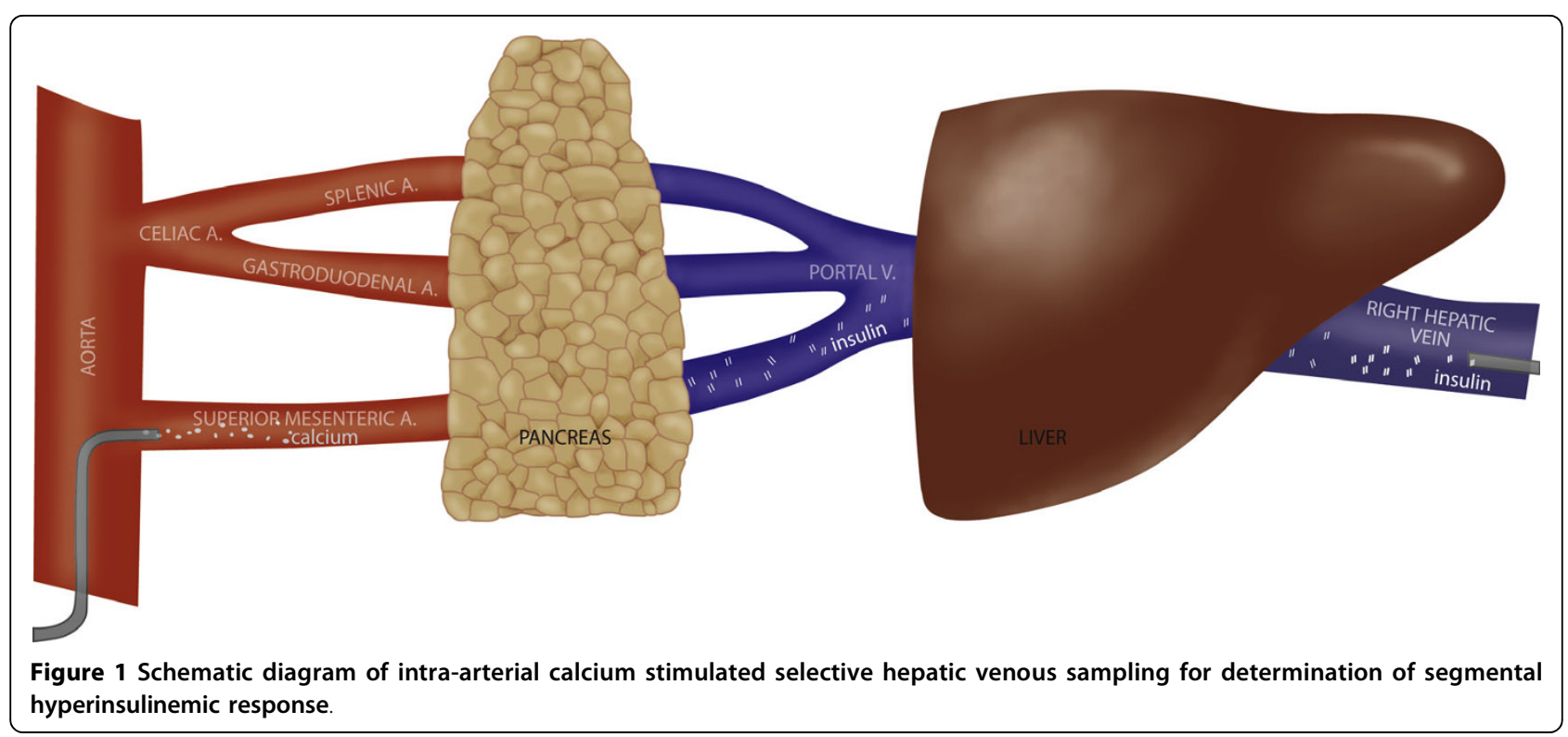

glucose was $0.8 \mathrm{mmol} / \mathrm{L}$, serum ketones were negative, serum insulin $445.6 \mathrm{pmol} / \mathrm{L}$ and serum C-peptide of $3.54 \mathrm{nmol} / \mathrm{L}$ - values $>18 \mathrm{pmol} / \mathrm{L}$ (insulin) and $>0.2$ $\mathrm{nmol} / \mathrm{L}$ (Cpeptide) are indicative of hyperinsulinemic hypoglycaemia. The confusion was completely relieved by oral glucose.

Computed tomography of the abdomen showed no focal abnormalities of the pancreas. Abdominal MRI showed good visualization of the pancreas with no dilatation of pancreatic ducts or focal enhancing masses in the pancreas or peripancreatic regions. Endoscopic ultrasound was negative, as was total body Indium ${ }^{111}$. octreotide scan.

Selective arterial catheterization and calcium stimulation testing was performed (Figure 1) with results shown in Table 1. The presence of a high calcium-stimulated insulin gradient in arteries supplying the body and tail of the pancreas suggested diffuse $\beta$-cell hyperplasia and a diagnosis of noninsulinoma pancreatogenous hypoglycaemia syndrome (NIPHS). The patient declined subtotal pancreatic resection and was successfully treated with Sandostatin 50 ug subcutaneously prior to each meal. No further significant hypoglycaemia has occurred.

\section{Conclusions}

Noninsulinoma pancreatogenous hypoglycaemia syndrome (NIPHS) was first described by Service et al. in 5 adults with symptoms of postprandial neuroglycopenia secondary to hyperinsulinemic hypoglycaemia. Diagnostic criteria for NIPHS includes a positive Whipple's triad (typical symptoms occurring in the setting of documented hypoglycaemia, relieved by glucose administration) following a mixed meal, a negative 72-h fast, negative peri-operative imaging studies for insulinoma, positive arterial calcium stimulation test, and islet hypertrophy or nesidioblastosis in pancreatic tissue [1]. This differs with the presentation of an insulinoma in that insulinomas are classically associated with fasting hyperinsulinemic hypoglycaemia and are usually identifiable on peri- or intraoperative imaging studies [2]. Diffuse calcium-stimulated hyperinsulinism from multiple segments of pancreatic vascular supply help to differentiate NIPHS from a solitary tiny insulinoma [3]. Furthermore, the neuroglycopenic symptoms of NIPHS distinguish it from "reactive" hypoglycaemia and the dumping syndrome sometimes seen in patients post-gastric bypass surgery $[2,4]$. No patients with NIPHS have been identified as having mutations in the Kir6.2 or SUR1 genes as

Table 1 Insulin levels in right hepatic vein before and after sequential selective arterial catheterization and intraarterial calcium infusion

\begin{tabular}{llll}
\hline Sampling distribution & $\begin{array}{l}\text { Pre-infusion hepatic vein } \\
\text { insulin }(\mathbf{m l U} / \mathbf{m l})\end{array}$ & $\begin{array}{l}\text { Peak post infusion hepatic vein } \\
\text { insulin (mlU/ml) }\end{array}$ & $\begin{array}{l}\text { Magnitude of calcium-stimulated } \\
\text { insulin increase }\end{array}$ \\
\hline Splenic artery & 3.9 & 62 & 15-fold \\
Gastroduodenal artery & 5.1 & 5.4 & No change \\
Superior mesenteric artery & 6.8 & 31 & $4-f o l d$ \\
\hline
\end{tabular}


occurs in certain children with a syndrome of familial hyperinsulinemic hypoglycaemia; however, the two groups do share similar histologic findings within the pancreas, namely, nesidioblastosis - a histologic diagnosis consisting of widespread $\beta$-cell hyperplasia along with diffuse proliferation and hypertrophy of islet cells from pancreatic ducts [1,2,5-7]. Recently, trophic factors and modulators of pancreatic morphology such as glucagon-like peptide 1 (GLP1) and islet neogenesis-associated protein (INGAP) have been implicated in the proposed pathologic changes leading to nesidioblastosis following upper gastrointestinal surgery $[4,6,8-10]$. To date, subtotal esophagectomy, subtotal gastrectomy, roux-en-Y gastric bypass, Billroth I partial gastrectomy, and Billroth II gastric bypass surgeries have all been associated with changes consistent with NIPHS, while gastric banding procedures have been shown to induce transient asymptomatic hyperinsulinemic hypoglycaemia in select patients $[4,6,8,11-13]$. Whether the change in gastrointestinal architecture contributes to the pathogenesis of NIPHS or whether the consequent weight loss and reduction of insulin resistance simply unmasks a primary underlying condition is still a matter of some debate $[4,8,9]$. In our patient's case, the onset of hypoglycaemia after the fundoplication after 14 years of quiescence suggests a causal or aggravating association but further case series would be needed to confirm such an association.

As it stands, gradient-guided surgical debulking is the only definitive treatment for NIPHS with pancreatic changes of nesidioblastosis [14]. While some have achieved desirable results with limited pancreatic resection, others have suggested that near-total or total pancreatectomy is the only definitive solution to this condition - as is the case for infants with diffuse nesidioblastosis and familial hyperinsulinemic hypoglycaemia $[11,12,15,16]$. Pharmacologically, symptoms have been shown to be adequately controlled with the use of diazoxide[6]. However, diazoxide use is not without potential adverse effects including hypotension and severe edema. Octreotide inhibits insulin secretion from both benign and malignant insulinomas via its effect on the G protein coupled somatostatin receptor [17]. Inhibition of insulin secretion from otherwise normal beta cells stimulated by sulfonylurea overdose demonstrates the ability of this drug to correct and prevent hypoglycaemia in beta cell hyperfunction outside of the tumour setting [18]. The present report confirms the utility of this medication to successfully treat diffuse beta cell hyperfunction/hyperplasia as well.

With the rising incidence of gastric bypass surgeries, it is important to be able to recognize the clinical picture of NIPHS and to investigate accordingly. This is the first description of the development of NIPHS following fundoplication surgery. Although octreotide has been successfully used to treat adult onset nesidioblastosis before, this is the first report of its use in post operative NIPHS [12].

\section{Abbreviations}

NIPHS: Noninsulinoma pancreatogenous hypoglycemia syndrome.

\section{Acknowledgements}

Written consent was obtained from the patient for publication of study. Funding: none.

\section{Author details}

${ }^{1}$ Division of Endocrinology, Faculty of Medicine, University of Calgary, Calgary, Alberta Canada. ${ }^{2}$ Division of Endocrinology, College of Medicine, Mayo Clinic, Rochester, MN, USA.

\section{Authors' contributions}

BB performed the literature review, conducted the chart review, and was responsible for the initial construction of the manuscript; GK was involved with the initial work-up and management of the patient, the diagnosis of the patient, extensive editing of the manuscript and generation of the computer graphic; FJS performed the selective arterial catheterization and calcium stimulation test at the Mayo Clinic, as well as edited the final version of the article. All authors gave final approval of the version to be published.

\section{Competing interests}

The authors declare that they have no competing interests.

Received: 27 August 2009 Accepted: 8 July 2010 Published: 8 July 2010

\section{References}

1. Service FJ, Natt N, Thompson GB, Grant CS, et al: Noninsulinoma pancreatogenous hypoglycaemia: a novel syndrome of hyperinsulinemic hypoglycaemia in adults independent of mutations in Kir6.2 and SUR1 genes. J Clin Endocrinol Metab 1999, 84:1582-9.

2. Gardner DG, Shoback DM: Greenspan's basic \& clinical endocrinology The McGraw-Hill Companies, Columbus OH, 8 2007, 763-4.

3. Wiesli $P$, Brändle $M$, Schmid $C$, et al: Selective arterial calcium stimulation and hepatic venous sampling in the evaluation of hyperinsulinemic hypoglycemia: potential and limitations. J Vasc Interv Radiol 2004, 15:1251-6.

4. Service GJ, Thompson GB, Service FJ, et al: Hyperinsulinemic hypoglycemia with nesidioblastosis after gastric-bypass surgery. $N$ Engl J Med 2005, 353:249-54.

5. Karnauchow PN: Nesidioblastosis in adults without insular hyperfunction. Am J Clin Path 1982, 78:511-3.

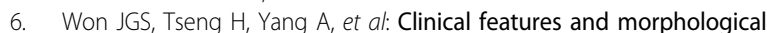
characterization of 10 patients with noninsulinoma pancreatogenous hypoglycaemia syndrome (NIPHS). Clin Endocrinol 2006, 65:566-78.

7. Hirshberg B, Alexander HR, Bartlett DL, et al: Nesidioblastosis in adults: a clinical enigma. J Clin Endocrinol Metab 2001, 86:2329.

8. Patti ME, McMahon G, Mun EC, et al: Severe hypoglycaemia post-gastric bypass requiring partial pancreatectomy: evidence for inappropriate insulin secretion and pancreatic islet hyperplasia. Diabetologia 2005, 48:2236-40.

9. Cummings DE: Gastric bypass and nesidioblastosis - too much of a good thing for islets? N Engl J Med 2005, 353:300-2.

10. Shultz KT, Francis AN, Nilsen LB, et al: Mechanism of postgastrectomy hypoglycemia. Arch Intern Med 1971, 128:240-6.

11. Clancy TE, Moore FD, Zinner MJ: Post-gastric bypass hyperinsulinism with nesidioblastosis: subtotal or total pancreatectomy may be needed to prevent recurrent hypoglycemia. J Gastrointest Surg 2006, 10:1116-9.

12. Tsujino $M$, Sugiyama $T$, Nishida $K$, et al: Noninsunlinoma pancreatogenous hypoglycemia syndrome: a rare case of adult-onset nesidioblastosis. Intern Med 2005, 44:843-7.

13. Scavini $M$, Pontiroli $A E$, Folli F: Asymptomatic hyperinsulinemic hypoglycemia after gastric banding. N Engl J Med 2005, 353:2822-3. 
14. Khoo T, Service FJ: 47-year-old woman with spells of slurred speech, blurred vision, and loss of consciousness. Mayo Clin Proc 2006, 81:1495-8.

15. Thompson GB, Service FJ, Andrews JC, et al: Noninsulinoma pancreatogenous hypoglycemia syndrome: an update in 10 surgically treated patients. Surgery 2000, 128:937-45.

16. Kaczirek K, Soleiman A, Schindl M, et al: Nesidioblastosis in adults: a challenging cause of organic hyperinsulinism. Eur J Clin Invest 2003, 33:488-92.

17. Vezzosi D, Bennett A, Courbon F, Caron P: Short and long term somatostatin analogue treatment in patients with hypoglycemia related to endogenous hyperinsulinism. Clin Endocrinol 2008, 68:904-11.

18. Fasano CJ, O'Malley G, Dominici P, Aguilera P, Latta DR: Comparison of octreotide and standard therapy versus standard therapy alone for the treatment of sulfonylurea-induced hypoglycaemia. Ann Emerg Med 2008 51:400-6.

\section{Pre-publication history}

The pre-publication history for this paper can be accessed here: http://www.biomedcentral.com/1471-230X/10/77/prepub

doi:10.1186/1471-230X-10-77

Cite this article as: Bernard et al: Hypoglycaemia following upper gastrointestinal surgery: case report and review of the literature. $B M C$ Gastroenterology 2010 10:77.

\section{Submit your next manuscript to BioMed Central} and take full advantage of:

- Convenient online submission

- Thorough peer review

- No space constraints or color figure charges

- Immediate publication on acceptance

- Inclusion in PubMed, CAS, Scopus and Google Scholar

- Research which is freely available for redistribution

Submit your manuscript at www.biomedcentral.com/submit 